\title{
Collaborations Between Speech-Language Pathology and Early Childhood Special Education Graduate Programs
}

\author{
Abbie Olszewski \\ University of Nevada, Reno, aolszewski@med.unr.edu \\ Lindsay Diamond \\ University of Nevada, Reno, Idiamond@unr.edu \\ Ann Bingham \\ abingham@unr.edu \\ DOI: https://doi.org/10.30707/TLCSD3.10lszewski
}

Follow this and additional works at: https://ir.library.illinoisstate.edu/tlcsd

Part of the Other Social and Behavioral Sciences Commons

\section{Recommended Citation}

Olszewski, Abbie; Diamond, Lindsay; and Bingham, Ann (2019) "Collaborations Between Speech-Language Pathology and Early Childhood Special Education Graduate Programs," Teaching and Learning in Communication Sciences \& Disorders: Vol. 3: Iss. 1, Article 4.

DOI: https://doi.org/10.30707/TLCSD3.10lszewski

Available at: https://ir.library.illinoisstate.edu/tlcsd/vol3/iss1/4

This Pilot Studies is brought to you for free and open access by ISU ReD: Research and eData. It has been accepted for inclusion in Teaching and Learning in Communication Sciences \& Disorders by an authorized editor of ISU ReD: Research and eData. For more information, please contact ISUReD@ilstu.edu. 


\title{
Collaborations Between Speech-Language Pathology and Early Childhood Special Education Graduate Programs
}

\author{
Abstract \\ There is limited documentation on interprofessional education (IPE) between graduate speech-language \\ pathology and early intervention/early childhood special education (EI/ECSE) programs. Because \\ collaborative relationships can lead to IPE, this study examined the current state of collaborative \\ relationships between speech-language pathology and EI/ECSE graduate programs and faculty. A mixed- \\ method design was conducted. Closed- and open-ended survey questions were sent to representatives of \\ 266 graduate speech-language pathology programs. There was a $29 \%(77 / 266)$ overall response rate. Out \\ of 77 graduate speech-language pathology programs, 27\% (21/77) indicated an emphasis in El, 17\% (13/ \\ $77)$ in ECSE, and 14\% (11/77) in El/ECSE combined. Respondents reported collaborative relationships in \\ the forms of shared coursework, clinical experiences, and research. Although some respondents engaged \\ in collaborative relationships, their reported barriers contribute to an instruction-practice gap. Program \\ respondents indicated that collaboration between graduate speech-language pathology and EI/ECSE \\ programs and faculty occurred in a variety of ways.
}

\section{Keywords}

collaborative relationships, interprofessional education, speech-language pathology students, early intervention/early childhood special education students, graduate training programs

\section{Cover Page Footnote}

The authors would like to thank the graduate speech-language pathology programs who responded to this survey. 


\section{Introduction}

Interprofessional education (IPE) is a pedagogical approach that has evolved over the years (National Center for Interprofessional Practice and Education, 2017). The goal of a contemporary IPE model is to educate students from two or more disciplines who learn about shared content alongside each other to facilitate collaboration and improve health outcomes (Buring et al., 2009; National Center for Interprofessional Practice and Education, 2017). Students within IPE programs develop academic and clinical competencies in shared values, effective communication, teambased assessment techniques, coordinated interventions, and apply values and ethics while working as members of interprofessional teams (Council on Academic Accreditation [CAA], 2017). Proficiency in these competencies can lead to future professional speech-language pathologists (SLPs) who deliver high quality care as members of an interprofessional team. Recently shared interest in this method of training has gained attention among graduate speechlanguage pathology programs as the CAA requires these programs to provide multiple opportunities for students to gain knowledge related to IPE competencies (CAA, 2017).

SLPs work with many different professionals from a variety of disciplines in both medical and educational settings. In medical settings, team members may include developmental pediatricians, occupational therapists (OT), physical therapists (PT), and physicians (Barton, Moore, \& Squires, 2012). Within early childhood educational settings, team members may include early interventionists, early childhood special education teachers, general education teachers, OTs, PTs, nurses, and families (Barton, Moore, \& Squires, 2012; Yang, Hossain, \& Sitharthan, 2013).

Although there are many team members who work individually with young children in early childhood settings, interprofessional teams can be more effective in meeting the educational outcomes of young children (Barton et al., 2012; Brebner, Jovanovic, Lawless, \& Young, 2016; Crais et al., 2004). In particular, the relationship between the SLP and early interventionist/early childhood special education (EI/ECSE) teacher is imperative for meeting the academic and communication needs of young children with disabilities. Within a clinical or educational setting, positive interprofessional relationships take time to cultivate a climate that supports the necessary communication to plan and deliver team-based services. Thus, graduate speech-language pathology programs can foster the development of collaborative relationships through the application of IPE with EI/ECSE programs. Students who participate in interprofessional opportunities in graduate school are more likely to implement team-based services as professionals (Crais et al., 2004; Goldberg, 2015).

Even though there is great benefit to IPE in the professional setting, there is a gap in the instruction of IPE (Pickering \& Embry, 2013; Self, Mitchell, Hess, Marble, \& Swails, 2017). Some graduate speech-language pathology programs have reported barriers to implementing IPE such as a dense curriculum, difficulty in the coordination of academic and clinical work, and possible lack of administrative support (Johnson, 2016; Pickering \& Embry, 2013; Rogers \& Nunez, 2013; Self et al., 2017). Due to these challenges, graduate speech-language pathology programs need to be creative in implementing IPE (Smith, 2010).

Learning how to effectively collaborate with other team professionals is a tenant of IPE (CAA, 2017). Collaboration occurs when two or more people share processes and resources to achieve a 
common goal (Jones \& Harris, 2014; Kinsella-Meier \& Gala, 2016). To support collaborative components of IPE, speech-language pathology faculty can model how to develop collaborative relationships with faculty across disciplines (CAA, 2017; Crais et al., 2004). Effective collaboration among faculty could provide opportunities for students to observe or participate in team-based activities across disciplines leading to future collaborations between departments and the implementation of IPE (Goldberg, 2015). Although IPE opportunities are required, it is unclear how graduate speech-language pathology programs are cultivating IPE with EI/ECSE programs through collaborative relationships.

\section{Interprofessional Education}

In 2009, a revival of interprofessional education stemmed from six national organizations in the areas of dentistry, nursing, medicine, osteopathic medicine, pharmacy, and public health who formed the Interprofessional Education Collaborative (IPEC). The goal of IPEC was to enhance pre-professional training of healthcare workers who will subsequently provide team-based care and improve patient health outcomes (Interprofessional Education Collaborative [IPEC], 2018). As healthcare providers, the American Speech-Language Hearing Association (ASHA) formed an Ad Hoc Committee on Interprofessional Education in 2013 to address several topics related to IPE, notably concepts and strategies for graduate speech-language pathology programs. This committee envisioned SLPs as valuable team members who could contribute beyond their discipline. Specifically, they can "prevent disease/disorders, reduce medical errors, promote patient safety, and improve population health" (ASHA, 2013, p.4). Accordingly, there is a general call for training programs to educate students to be productive interprofessional team members while providing evidence-based services (Buring et al., 2009; IPEC, 2016; CAA, 2017).

\section{Speech-Language Pathology and EI/ECSE Faculty Collaborations}

Finding collaborative faculty partners within higher education institutions is a key step in successful implementation of IPE (Pickering \& Embry, 2013). There are over one million infants and toddlers (ages 0 to 3 years) and young children (ages 3 to 5 years) that receive EI/ECSE services in the United States (U.S. Department of Education, 2016). Of the children ages 3 to 5 years old, $43.7 \%$ qualify for services under the category of Speech Language Impairment under Part B of the Individuals with Disabilities Education Act (IDEA; U.S. Department of Education, 2016). Under IDEA, these children are served by EI/ECSE teachers and related service personnel across a continuum of educational settings based on individual needs, ranging from self-contained to general education classrooms.

While SLPs deliver services focusing on communication, EI/ECSE teachers provide specialized instruction to these young children with disabilities. This means that these children will likely be served by both SLPs and EI/ECSE teachers. Thus, a collaboration between SLPs and EI/ECSE teachers is a natural collaboration that could improve the academic outcomes of young children with disabilities. Early childhood is an important period of development for young children's language and communication skills (Brebner et al., 2016). SLPs and EI/ECSE teachers should understand each other's training and expertise in order to work together in providing coordinated services that improve cognitive, language, communication, and literacy abilities of young children with disabilities (Barton, Moore, \& Squires, 2012; Brebner et al., 2016). 
While delivering services, the SLP will model facilitation of communication-enhancing strategies with the child to promote meaningful participation in the natural environment (McDonald et al., 2015). The SLP may also coach the EI/ECSE teacher in ways to further integrate specific communication opportunities across everyday routines and activities. Through this interaction, the SLP and EI/ECSE teacher will begin to develop a relationship that promotes collaboration in planning and implementation of communication strategies. Thus, a successful collaboration will occur when the SLP and EI/ECSE teacher understand each other's roles (Barton, Moore, \& Squires, 2012; Copple, Bredekamp, \& National Association for the Education of Young Children [NAEYC], 2009).

During academic instruction, the EI/ECSE teacher can demonstrate instruction of academic content, social skills, literature activities, and daily routines to teach the SLP about the goals and functions of the early childhood classroom environment. After observing the EI/ECSE teacher, the SLP can discuss the implementation of communication strategies. Because early childhood is such an important developmental time in which young children learn many skills, it is important for the SLP and the EI/ECSE teacher to understand how to leverage each other's skills to best support communication skills across all developmental domains. Together, the SLP and EI/ECSE teacher can collaborate to design instruction during snack time, learning centers, playgroups, and dramatic play that will promote the use of communication skills and support academic growth.

\section{Training of Speech-Language Pathology and EI/ECSE Graduate Students}

Graduate speech-language pathology programs are typically on-site and two years in length. The first year and a half often consists of academic courses in addition to diagnostic and therapeutic clinical experiences, whereas during the last semester students are assigned one to two clinical placements off-site (ASHA, 2018). Similarly, EI/ECSE graduate students complete a two-year graduate program that may include face-to-face, hybrid, and online courses. EI/ECSE students are also required to complete field based experiences, often in both EI and ECSE school-based settings (Division for Early Childhood, 2017). However, some EI/ECSE graduate programs may be offered exclusively online making collaborations between speech-language pathology and EI/ECSE students more difficult.

Ideally, graduate students from speech-language pathology and EI/ECSE should be trained together to learn how to provide team-based services within early childhood environments that are comprehensive and coordinated to meet the learning needs of young children with disabilities (American Speech-Language Hearing Association [ASHA], 2008). Although both graduate programs have limited flexibility in course schedules and field work, it is possible to create IPE experiences within these training programs because both have academic and clinical (field work) requirements. During training, IPEC competencies can be used as a framework to implement IPE between graduate speech-language pathology and EI/ECSE programs. We postulate that graduate students in speech-language pathology and EI/ECSE could have shared learning opportunities in the classroom through shared coursework and/or clinical experiences.

An example of IPE for speech-language pathology students in graduate school would involve speech-language pathology students learning alongside ECSE graduate students while taking a 
shared academic course. Coursework topics of mutual interest to these pre-professionals could include topics such as child development, families, assessment, curriculum, and research (Barton et al., 2012). A specific shared course could be Serving Young Children with Disabilities and Their Families. All graduate speech-language pathology students would have the opportunity to practice meeting competencies with and from students in their program as well as graduate students in EI/ECSE.

Another example of IPE can be during clinical work. Instead of serving young children with disabilities in a university's speech and hearing clinic, graduate students could serve these children in their natural academic environments alongside students in EI/ECSE program. The graduate speech-language pathology student will be targeting communication goals and can learn how to embed these goals within classroom activities while working simultaneously with the EI/ECSE graduate student on the child's academic goals. Learning to provide these services using an IPE model is likely to extend to providing collaborative services as a professional upon graduation (Goldberg, 2015).

\section{IPE Models}

In healthcare training programs, there are variety of approaches used to implement IPE models, where students learn alongside each other during coursework, shared clinical experiences, online discussions and activities, and team-based experiences (Johnson, 2016). Speech-language pathology students have been included in a handful of university IPE models that use IPEC competencies to guide IPE experiences (Johnson, 2016). For example, students from 11 different health science programs at the University of Toronto participate in four core learning activities: (a) Teamwork: Your Future in Healthcare, (b) Conflict in Interprofessional Life, (c) Case-Based Learning Activity, and (d) IPE Component in a Practice Setting in addition to elective learning activities (University of Toronto, 2016). Students at University of South Carolina participate in an interprofessional practice experience that includes students from medicine, nursing, pharmacy, physical therapy, public health, and social work (University of South Carolina, 2018). The MGH Institute of Health Professions offers hands-on collaborative experiences through a three-course sequence that is integrated into their plan of study (MGH Institute of Health Professions, 2017).

Some graduate speech-language pathology programs have designed their own curriculum for IPE. For example, the Communication Disorders and Sciences Department at the University of Oregon was awarded a federal personnel preparation grant that focused on training pre-professionals to fulfill SLP positions in EI/ECSE settings (Barton et al., 2012). This interprofessional servicedelivery model was implemented and included coursework, seminars, practicum activities, exposure to medical clinics, and faculty collaborations. Interdisciplinary team-based partners included community EI/ECSE teachers, OTs, psychologist, and PTs. Results indicated clinical experiences such as home visiting and family coaching played a critical role for graduating students when deciding to seek work in early intervention settings (Barton et al., 2012).

In addition, faculty in the Department of Communication Sciences and Disorders and Department of Special Education at the University of Wisconsin-Whitewater used a collaborative consultation IPE model to fill an instructional-practice gap (Miolo \& DeVore, 2016). Students were in their first year of a graduate speech-language pathology program and third year of an undergraduate 
program in ECSE. The IPE experience consisted of a semester-long project that was a part of current respective curricula. Students learned alongside each other in "university classroom, small group team meetings inside and outside of the classroom, and field-based activities conducted in community-based preschool settings" (Miolo \& DeVore, 2016, p. 82). Findings from this study indicated students were able to engage in the collaborative consultation model and meet IPE competencies (Miolo \& DeVore, 2016).

In summary, implementation of IPE in graduate speech-language pathology programs is on the rise, as it is now an accreditation requirement of the CAA (CAA, 2017). However, graduate programs find it challenging to provide IPE opportunities due to scheduling, timing, and institutional support issues (Johnson, 2016; Pickering \& Embry, 2013). Further, there is limited documentation of IPE between speech-language pathology and EI/ECSE programs in the literature (Miolo \& DeVore, 2016). With so many young children receiving special education and speechlanguage pathology services, it would benefit young children with disabilities if graduate speechlanguage pathology programs trained students to collaborate with graduate EI/ECSE students. Because an instruction-practice gap exists (Miolo \& DeVore, 2016), there is much to be learned about the implementation of IPE and collaborative relationships among faculty in graduate speechlanguage pathology programs and EI/ECSE.

\section{Purpose}

Although professional organizations such as ASHA and the Division for Early Childhood of the Council for Exceptional Children (DEC/CEC) encourage IPE, graduate speech-language pathology students receive limited training in collaboration in graduate school (Howell, Wittman, \& Bundy, 2012; Self et al., 2017). To date, there is minimal documentation of IPE in graduate speech-language pathology programs and even fewer between speech-language pathology and EI/ECSE students (Miolo \& DeVore, 2016). However, it is likely that collaborative training experiences could be infused within graduate speech-language pathology programs. Therefore, the aim of this study was to describe current collaborative relationships among departments and faculty in speech-language pathology and EI/ECSE graduate programs.

\section{Method}

\section{Participants and Procedures}

This study was approved by Institutional Internal Review Board (\#995424-1). A graduate research assistant identified graduate programs on ASHA's website (http://www.asha.org/edfind/search.aspx) that met the following inclusion criteria: (a) university has a graduate program in speech-language pathology and (b) the graduate speech-language pathology program is accredited by the CAA. This list of schools was used to search the internet for the school website and contact information for graduate program coordinators and department chairs. Representatives were invited via email to participate in a survey designed in Survey Monkey. The first round of emails was sent in January 2017. Five hundred fifty-three graduate program coordinators and department chairs that represented 266 graduate programs were invited to participate in the survey. Eleven days later, a second round of emails was sent thanking those that participated in the study and re-inviting those who did not participate. 


\section{Survey}

A convergent mixed method research design was utilized. Responses were collected using a combination of closed- and open-ended survey questions. The authors designed a brief survey based on a semi-structured interview conducted by Nochajski (2002) who gained insight on collaboration among regular educators, special educators, OTs, PTs, and SLPs in an inclusive school district setting. Professional educators were asked five guiding questions regarding collaboration. Specifically, the educators were asked to define the meaning of collaboration, the extent of collaborations between regular and special educators and therapists within school settings, their perspectives regarding the advantages and barriers, and suggestion for improving collaboration (Nochajski, 2002).

Thus, the survey for the current study focused on collaborative concepts documented in the literature (Barton et al., 2012; Nochajski, 2002). Specifically, representatives of programs were asked questions regarding their program's emphasis in EI and/or ECSE, the presence of a graduate program in EI and/or ECSE at their university, types of coursework offered, set of competencies used, the existence of departmental collaborative relationships with EI/ECSE, and collaborative relationships between faculty across disciplines. In addition to this survey, EI/ECSE program faculty were also given a separate survey. Results from the survey for EI/ECSE faculty will be presented in a different manuscript.

Because there are so many definitions for IPE across publications and professions (Buring et al., 2009; Goldberg, 2015), the authors of this study were interested in focusing on collaborative relationships, a tenet of IPE. The collaborative relationships could be an artifact of IPE implementation or could eventually lead to new IPE (Goldberg, 2015). For the purpose of this study, collaborative relationships were operationally defined for survey respondents as interactions between the faculty in speech-language pathology departments and faculty in special education, EI, or ECSE departments at universities (Jones \& Harris, 2014; Kinsella-Meier \& Gala, 2016). Further, examples of collaborative relationships were provided (i.e., research projects, teaching, and service) to guide survey respondents to answer questions about collaboration.

The survey contained a total of 10 questions: one yes/no eligibility question, seven yes/no questions, and two open-ended questions. The eligibility question asked whether the program was accredited. The seven yes/no questions asked about the graduate program's emphasis in EI/ECSE; collaborative relationships with special education, early childhood, and early intervention departments; the existence of graduate programs in EI/ECSE at their university; coursework offerings; and coursework competencies. To identify any type of collaborative experiences, one open-ended question asked the participants to describe their collaborative experiences. To determine survey sample characteristics, the last open-ended question requested university affiliation. (See Appendix for specific survey questions.)

The authors followed four steps in developing questions for survey instruments (Evergreen, Gullickson, Mann, \& Welch, 2011). First, simple questions were developed using familiar words, uncomplicated sentence structures, and limited number of words per sentence. Second, survey questions were developed to ask one concept within a question at a time. Third, question stems 
and responses were reviewed for consistency throughout the survey. Fourth, a Flesch Reading Ease score of 12.5 and a Flesch-Kincaid Grade Level of 14.1 indicated that the questions were readable by college students. Based on these scores, the survey reading level was appropriate for survey respondents as it was sent to university professors who were college graduates.

The authors also followed four steps for instrument validation (Evergreen et al., 2011). First, the researchers operationally defined the term collaborative relationships for survey respondents within the survey. Second, relevant elements used to define the content of this survey were gathered from the literature (Barton et al., 2012; Miolo \& DeVore, 2016; Nochajski, 2002). Third, survey questions were then developed for different areas of inquiry. Fourth, to ensure content validity, the survey was reviewed and piloted by three university professors- a speech-language pathology professor, an EI/ECSE professor with a graduate degree in speech-language pathology, and a professor in EI who specializes in survey design and administration. Following these reviews of the survey, the faculty member and the first author discussed suggestions and edits to improve the validity of the survey. After all edits were made, the survey was reviewed by all authors and the reviewers who deemed the content and eligibility requirements to be appropriate.

\section{Data Analysis}

Quantitative and qualitative data analyses were used to understand the nature of collaborative relationships in providing graduate training between graduate speech-language pathology and EI/ECSE programs.

Quantitative Analysis. Eight of the nine survey questions required a yes or no response. Because not all questions in the survey were required, each question's response was calculated separately to provide a percentage of the responses. These percentages allowed for a better understanding of the characteristics of the respondent's graduate training programs in speech-language pathology.

To calculate the number of graduate speech-language pathology programs that have an emphasis in (a) EI, (b) ECSE, or (c) EI and ESE, the number of yes responses to survey questions 2, 3, and 4 were added separately and then divided by the total number of responses to obtain a percentage of the total number of graduate programs who have an emphasis in EI, ECSE, or EI and ECSE.

To determine the number of graduate speech-language pathology programs that offer specific courses related to EI/ECSE, the number of yes responses to survey question 7 was added for each course and then divided by the total number of responses to obtain a percentage.

To determine the number of speech-language pathology faculty engaged in collaborative relationships across disciplines at their university, the number of yes responses to survey question 5 were added for each area of collaboration and divided by the total number of responses to obtain a percentage of graduate programs who have collaborations with special education, early childhood special education, and early intervention faculty.

Qualitative Analysis. To determine the type of collaborative relationships speech-language pathology faculty engage in, an inductive, constant comparative approach was used to analyze qualitative responses to question 9 to allow for key concepts to emerge (Miles, Huberman, \& 
Saldana, 2014; Thomas, 2006). This systematic approach of analysis focuses on identifying and establishing links between themes present in the data leading to the foundation of a clear framework (Thomas, 2006). The first step in the qualitative data analysis consisted of organizing and cleaning data. During the cleaning process, the second author extracted 45 responses that were left blank or specifically indicated a response of none, not any, not that I am aware of, or not any at this time. After these responses were removed from the data-set, a total of 36 open-ended responses remained.

The second step of the qualitative data analysis was to complete the first cycle of coding. During the first cycle of coding, the first and second author conducted independent open-coding sessions. This process provided each author the opportunity to become familiar with the responses by reading each response multiple times, which allowed for the formulation of themes and domains based on the individual responses (Thomas, 2006). Authors assigned each response a version of a level-1 code and a level-2 subcode. A level-1 code referred to a general theme, whereas a level-2 subcode was a sub-theme of the level-1 code.

The third step of the qualitative data analysis was to complete the second cycle of coding. During this second cycle, the first and second authors verbally reviewed the level-1 and level- 2 codes from the first cycle. This second cycle provided the opportunity to focus on patterns, themes, or constructs to further group similar responses into a general framework (Miles et al., 2014; Thomas, 2006). Both researchers reached consensus on the wording for level-1 and level- 2 codes prior to generating the conceptual framework.

Lastly, to ensure interrater reliability of the qualitative data analysis, the third author reviewed the data and independently identified level-1 codes and level-2 subcodes. The third author's codes were compared to the first and second authors' codes. Slight adjustments were made to ensure the data could be coded reliably. Point-by-point interrater reliability for level-1 codes of shared coursework was 94\% (15/16), clinical experiences was 92\% (11/12), and research was 88\% (7/8). Data for level-2 subcodes were coded collaboratively. This process also led to the development of the conceptual framework used to categorize the qualitative responses.

\section{Results}

\section{Descriptive Results}

The survey was sent to representatives of the 266 CAA accredited graduate speech-language pathology programs. Initially, there were 80 respondents. It was noted that there were two respondents from two schools. The authors decided to include the responses from the first respondents and exclude the responses from the second respondents. In another instance, one school answered the eligibility question but did not complete the survey. This respondent was excluded from the study. The final response rate of graduate speech-language pathology programs was $29 \%$ (77/266). In addition to the response rate, other factors were considered in judging the study quality and validity. Specifically, the study was deemed acceptable based on methodologies used in recruitment, attempts made to raise the response rate, and a description of the participants (Morton, Bandera, Robinson, Atatoa Carr, 2012). 
The number of survey respondents who answered the closed ended-survey questions is presented in Table 1. Of the 77 programs that were included in the results, 43 indicated their school affiliation. Out of these 43 programs, respondents were inclusive of all United States Census Regions with a majority from the South followed by the Midwest, West, and Northeast. To maintain anonymity of schools, a visual representation of the respondents by region is provided in Figure 1.

Table 1

Survey Question Results

\begin{tabular}{|c|c|c|c|}
\hline Question & $\begin{array}{c}\text { Number of } \\
\text { Respondents }\end{array}$ & Yes & No \\
\hline $\begin{array}{l}\text { 1. Do you have an accredited graduate program in } \\
\text { speech-language pathology? (eligibility question) }\end{array}$ & 81 & $\begin{array}{c}80 \\
(99 \%)\end{array}$ & $\begin{array}{c}1 \\
(1 \%)\end{array}$ \\
\hline $\begin{array}{l}\text { 2. Does your Speech-Language Pathology graduate } \\
\text { program have an emphasis in Early Intervention ( } 0 \text { to } 3 \\
\text { years)? }\end{array}$ & 77 & $\begin{array}{c}21 \\
(27 \%)\end{array}$ & $\begin{array}{c}56 \\
(73 \%)\end{array}$ \\
\hline $\begin{array}{l}\text { 3. Does your Speech-Language Pathology graduate } \\
\text { program have an emphasis in Early Childhood Special } \\
\text { Education ( } 3 \text { to } 8 \text { years)? }\end{array}$ & 77 & $\begin{array}{c}13 \\
(17 \%)\end{array}$ & $\begin{array}{c}64 \\
(83 \%)\end{array}$ \\
\hline $\begin{array}{l}\text { 4. Does your Speech-Language Pathology graduate } \\
\text { program have an emphasis in both Early } \\
\text { Intervention/Early Childhood Special Education } \\
\text { combined? }\end{array}$ & 77 & $\begin{array}{c}11 \\
(14 \%)\end{array}$ & $\begin{array}{c}66 \\
(86 \%)\end{array}$ \\
\hline \multicolumn{4}{|l|}{$\begin{array}{l}\text { 5. Does your Speech-Language Pathology graduate } \\
\text { program have a collaborative relationship with: }\end{array}$} \\
\hline Special Education Department? & 72 & $\begin{array}{c}28 \\
(39 \%)\end{array}$ & $\begin{array}{c}44 \\
(61 \%) \\
\end{array}$ \\
\hline Early Childhood Special Education Department? & 71 & $\begin{array}{c}21 \\
(30 \%)\end{array}$ & $\begin{array}{c}50 \\
(70 \%)\end{array}$ \\
\hline Early Intervention Department? & 70 & $\begin{array}{c}12 \\
(17 \%)\end{array}$ & $\begin{array}{c}58 \\
(83 \%)\end{array}$ \\
\hline $\begin{array}{l}\text { 6. Does your university have a graduate program in } \\
\text { Early Intervention/Early Childhood Special Education? }\end{array}$ & 72 & $\begin{array}{c}37 \\
(51 \%)\end{array}$ & $\begin{array}{c}35 \\
(49 \%)\end{array}$ \\
\hline \multicolumn{4}{|l|}{$\begin{array}{l}\text { 7. Does coursework in your Speech-Language } \\
\text { Pathology graduate program include entire classes } \\
\text { focused on: }\end{array}$} \\
\hline $\begin{array}{r}\text { Foundations in Early Intervention } \\
\text { (Description: Guiding principles of EI/ECSE; typical } \\
\text { and atypical child development)? }\end{array}$ & 33 & $\begin{array}{c}22 \\
(67 \%)\end{array}$ & $\begin{array}{c}11 \\
(33 \%)\end{array}$ \\
\hline $\begin{array}{r}\text { Assessment and Evaluation of Young Children } \\
\text { (Description: Best practices in assessment for } \\
\text { screening, eligibility, programming, and evaluation } \\
\text { with young children)? }\end{array}$ & 33 & $\begin{array}{c}23 \\
(70 \%)\end{array}$ & $\begin{array}{c}10 \\
(30 \%)\end{array}$ \\
\hline $\begin{array}{r}\text { Family-Guided Early Intervention } \\
\text { (Description: Principles and practices for working with } \\
\text { families in EI/ECSE; family systems theory, family } \\
\text { assessment)? }\end{array}$ & 33 & $\begin{array}{c}16 \\
(48 \%)\end{array}$ & $\begin{array}{c}17 \\
(52 \%)\end{array}$ \\
\hline
\end{tabular}




\begin{tabular}{|r|c|c|c|}
\hline $\begin{array}{r}\text { Curriculum Approaches in Early Childhood } \\
\text { (Description: Curricular approaches for working with } \\
\text { young children in early childhood settings; designing } \\
\text { and implementing early childhood curricula)? }\end{array}$ & 33 & $\begin{array}{c}8 \\
(24 \%)\end{array}$ & $\begin{array}{c}25 \\
(76 \%)\end{array}$ \\
\hline $\begin{array}{l}\text { 8. Does coursework in your Speech Language } \\
\text { Pathology graduate program use the following World } \\
\text { Health Organization's "Interprofessional Core } \\
\text { Competencies"? }\end{array}$ & 31 & 23 & 8 \\
\hline Teamwork & 31 & $\begin{array}{c}23 \\
(74 \%)\end{array}$ & $\begin{array}{c}8 \\
(26 \%)\end{array}$ \\
\hline Roles/ Responsibilities & 31 & $\begin{array}{c}24 \\
(77 \%)\end{array}$ & $\begin{array}{c}7 \\
(23 \%)\end{array}$ \\
\hline Communication & 30 & 22 & 8 \\
$(73 \%)$ & $(77 \%)$ \\
\hline Learning and Reflection & 31 & 21 & 10 \\
$(68 \%)$ & $(32 \%)$ \\
\hline Patient (Child) & 31 & 23 & 8 \\
$(74 \%)$ & $(26 \%)$ \\
\hline
\end{tabular}

Note. Percentage is the number of yes or no responses out of the total respondents.

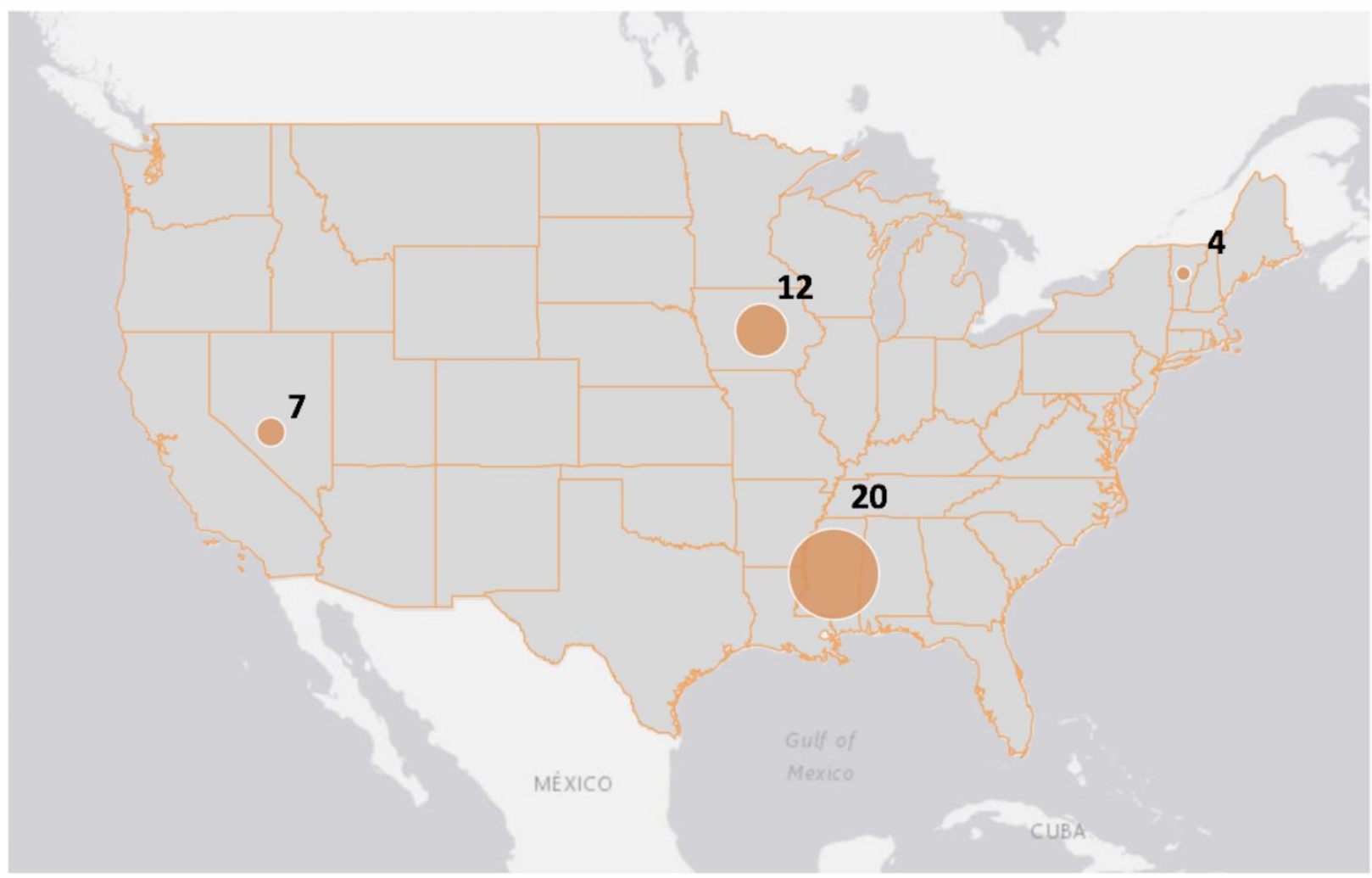

Figure 1. Visual representation of the 43 programs that indicated school affiliation. Respondents were from all United States Census Regions-- the West $(n=7)$, Midwest $(n=12)$, Northeast $(n=$ $4)$, and the South $(n=20)$. 


\section{Quantitative Results}

Not all respondents answered all questions. (See Table 1 for responses to quantitative survey questions.) To determine the presence of EI/ECSE emphases within graduate speech-language pathology programs, survey questions were analyzed for emphasis in EI, ECSE, or EI/ECSE combined. Results indicated 27\% (21/77) of graduate programs that responded to the survey have an emphasis in EI, 17\% (13/77) in ECSE, and 14\% (11/77) in EI/ECSE combined.

To better understand potential department collaborations between graduate speech-language pathology programs and graduate EI/ECSE programs, respondents were asked if there was a graduate program in EI/ECSE at their university. Results indicated 51\% (37/72) of universities with graduate speech-language pathology programs who responded to the survey also had a graduate program in EI/ECSE, whereas 49\% (35/72) did not.

To identify graduate speech-language pathology programs that offered EI/ECSE focused courses, four survey questions were analyzed to determine whether graduate coursework within the areas of foundations, assessment, family, and curriculum were offered (Barton et al., 2012). See Table 1 for course descriptions that were selected from an IPE model in the literature (Barton et al., 2012). Sixty-seven percent (22/33) who responded to the survey have courses in foundations, 70\% (23/33) in assessment, 49\% (16/33) in family, and 24\% (8/33) in curriculum.

To determine whether graduate speech-language pathology programs have collaborative relationships with EI, ECSE, or EI/ECSE departments, programs were asked about these relationships. Results indicated 39\% (28/72) of graduate programs who responded to the survey have collaborations with special education departments, 30\% (21/71) with ECSE departments, $17 \%$ (12/70) in EI departments. Additionally, 51\% (37/72) of programs who responded to the survey indicated that their university has a graduate program in EI/ECSE.

\section{Qualitative Results}

To determine the range of collaborative relationships between faculty in speech-language pathology and EI/ECSE, an open-ended prompt was given. Forty-five percent (29/65) indicated there were no faculty collaborative relationships by responding "none" or "not applicable." Of the 36 remaining programs, respondents indicated that faculty collaborative relationships ranged from individual faculty collaborations to the design and implementation of programmatic policies. To further describe the responses regarding faculty collaborative relationships of the 36 programs, responses were analyzed and coded into a conceptual framework. There were three major categories that emerged and were coded as level-1 codes: (1) shared coursework, (2) clinical experiences, and (3) research. (See Table 2 for numeric results of qualitative survey question respondents and Figure 2 for a visual representation of the conceptual framework related to the qualitative results.) 
Table 2

Number of Respondents for Qualitative Results

\begin{tabular}{|c|c|}
\hline Themes & Number of Respondents \\
\hline Shared Coursework & 16 \\
\hline Courses & 9 \\
\hline Instructor & 6 \\
\hline Clinical Experiences & 12 \\
\hline On-Campus & 9 \\
\hline Off-Campus & 4 \\
\hline Research & 8 \\
\hline Studies & 7 \\
\hline Grants & 6 \\
\hline
\end{tabular}

Note. Total survey responses were not mutually exclusive to level-1 codes and level-2 subcodes. Some responses included zero, one, or two level-2 subcodes, in which case these numbers will not total level-1 subcodes. Level-1 codes included Shared Coursework, Clinical Experiences, and Research. Level-2 subcodes included Courses, Instructor, On-Campus, Off-Campus, Grants, and Studies.

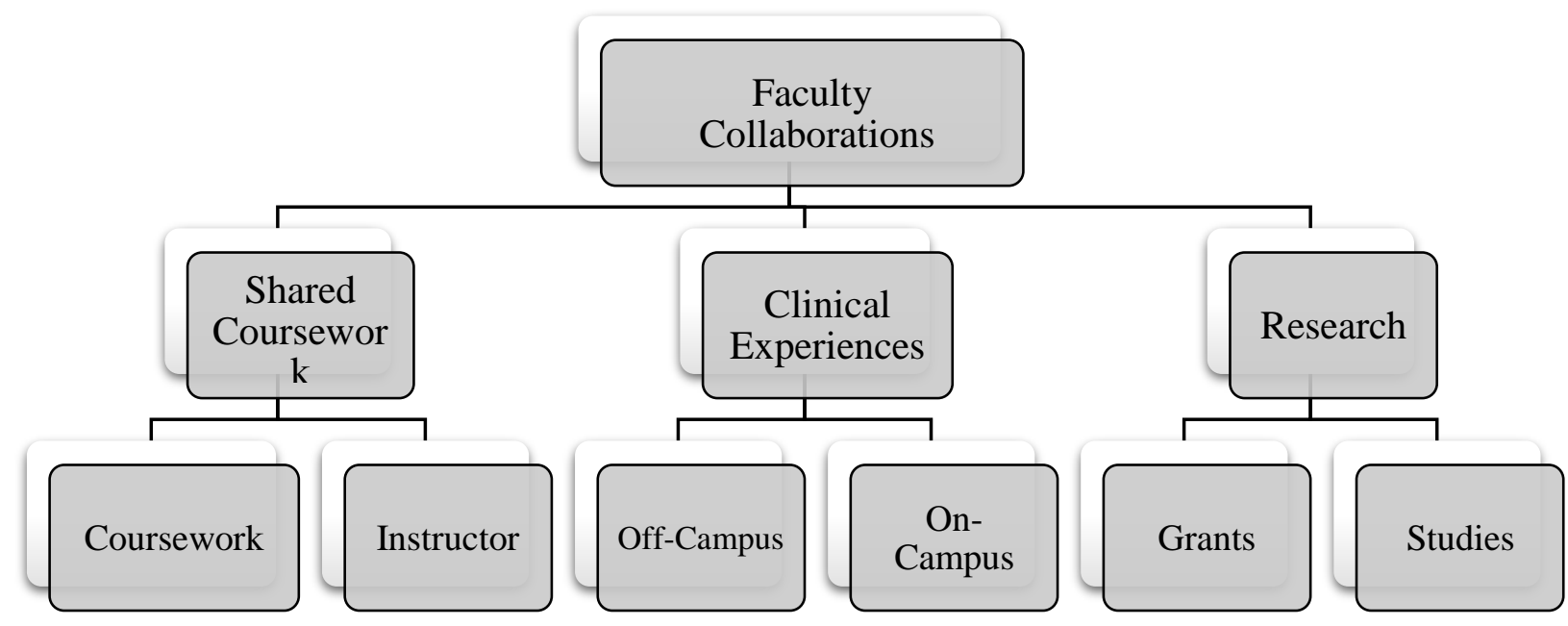

Figure 2. Qualitative results of survey question 9 indicated that faculty were engaging in collaborative relationships that were placed into three major codes: (1) shared coursework, (2) clinical experiences, and (3) research. Responses in these categories were further delineated into subcodes. 
Shared Coursework. Survey respondents $(n=16)$ indicated shared coursework as a collaborative relationship between colleagues in speech-language pathology and EI/ECSE. Programs indicated that the purpose of students participating in shared coursework was to improve the development of relationships among pre-professionals who will work with young children. Upon further analysis, these responses provided information regarding the type of course and the instructor who taught the course. Therefore, responses in this category were organized into two level-2 subcodes, coursework and instructor.

The first subcode coursework included responses $(n=9)$ ranging from "optional integrated" courses to "mandatory courses included within a program of study." An example of an optional course was described by one program who works with multiple disciplines (e.g., education, PT, OT, etc.) that provided optional shared coursework opportunities for students. This program also indicated that although the shared coursework was available, not all students participated as it would be counted as additional credits outside of the usual program of study.

Graduate programs who responded to the survey ranged in their requirements for mandatory shared coursework. There was only one graduate speech-language pathology program that indicated one mandatory "birth to 5" course for speech-language pathology students as part of the curriculum. This graduate program did not specify if this course was offered by speech-language pathology or EI/ECSE faculty. Two graduate programs described mandatory courses for students in speechlanguage pathology and EI/ECSE. For example, "students from these majors are required to take our Speech Language Development Course and our students are required to take an introductory to early childhood special education class." One graduate program indicated multiple mandatory courses within "Speech-Language, Special Education, and Early Childhood Education departments." The unique nature of this collaboration indicates "mixed groups of majors within these classes." In addition to these specific shared coursework examples, other graduate programs reported that they offered multiple shared seminars with students from EI/ECSE that integrated course activities to promote collaboration among students.

Although a majority of the responses indicated positive collaborative relationships surrounding shared coursework, one program stated that previous attempts were made to share coursework, but efforts were difficult in that "our curriculum area is packed" and that "no specific efforts 'stuck." Respondents indicated difficulty in developing collaborative relationships when implementing coursework due to inflexible course sequences.

The second subcode, instructor, included responses $(n=6)$ that described the type of instructor involved in delivering content in both shared coursework and seminars. Specifically, programs reported that instructors were SLPs, EI/ECSE faculty, other university faculty, and current professionals in the field of early childhood (i.e., SLP, OT, PT). Four of the six programs indicated guest lecturer as a specific type of instructor. Programs described these guest lecturers as professionals currently working in the local community or at neighboring universities. However, specific details about the content the guest lecturers presented were not discussed.

Clinical Experiences. Survey respondents $(n=12)$ indicated the ability to engage in clinical experiences provided an environment that fostered collaborative relationships among speech- 
language pathology and EI/ECSE graduate students. Analysis of the responses surrounding clinical experiences were placed into one of two subcategories, on-campus $(\mathrm{n}=9)$ and off-campus $(\mathrm{n}=4)$. One program reported both on-campus and off-campus clinical experiences.

Nine programs who reported having on-campus clinical experiences indicated that these experiences were within university child development centers, campus preschools and childcare programs, and speech and hearing clinics. One program also indicated having an interprofessional autism clinic. Further exploration of the data indicated that four of the nine programs provided graduate students the opportunity to observe and conduct speech-language assessments and screenings, design treatment plans, evaluate progress of patients, and consult with clients under the supervision of a faculty member. While a majority of the programs indicated that graduate speech-language pathology students participated in a variety of clinical on-campus experiences, most did not meet the new definition of IPE (IPEC, 2017).

Four programs who reported having off-campus clinical experiences indicated that these external experiences were provided in collaboration with locations such as local Head Start sites, community childcare centers, and local preschools. Out of the four programs, one program indicated that the speech-language pathology graduate students designed inclusive intervention plans as part of the educational team of individuals who worked with young children with disabilities.

Research. Survey respondents $(n=8)$ indicated collaborative relationships in the area of research. The types of research collaborations that occurred across program faculty were separated into two subcategories, grants $(n=6)$ and studies $(n=7)$. Some programs reported both grant and studies.

Findings indicated that six program faculty participated in collaborative grant activities, which were supported by external funding. Personnel preparation grants and Leadership Education in Neurodevelopmental Disabilities (LEND) grants were the two sources of funding mentioned. Out of the six programs, three programs identified their collaborative grant partners. These partners included faculty from ECSE, special education, social work, psychology, and school psychology departments.

Program faculty also reported collaborative relationships with faculty from other disciplines while conducting research studies. Out of seven programs that indicated collaboration on research studies, three faculty reported having productive collaborative relationships with EI and ECSE faculty. However, specific details about the collaborative relationships were not provided.

\section{Discussion}

In light of current IPE accreditation requirements by CAA and recommended practices by ASHA, there is little documentation of how to address the instruction-practice gap in higher education (Pickering \& Embry, 2013; Self et al., 2017). Graduate speech-language pathology programs are beginning to explore the implementation of IPE on their campuses. Of the studies from the literature that described IPE in speech-language pathology, even fewer described IPE between graduate speech-language pathology programs and graduate programs in EI/ECSE (Miolo \& Devore, 2016). 
Results from this study found that even when there are graduate EI/ECSE programs on the same campus as graduate speech-language pathology programs, there continues to be an instructional gap in IPE between these two departments. Findings from this study indicated a measurable gap between the number of university campuses with graduate speech-language pathology and EI/ECSE programs and the number of departmental or faculty collaborative relationships. Additionally, although implementing collaborative relationships between graduate speechlanguage pathology and EI/ECSE programs may lead to better trained SLPs, the actual implementation requires thoughtful attention. As many programs noted in the qualitative results, implementation may be challenging due to lack of interested collaborators, limited funding, and additional coursework in an already intensive program of study. This finding supports the challenges reported in relation to the implementation of IPE documented in the literature (Pickering \& Embry, 2013; Self et al., 2017).

Quantitative findings also reported a small number of graduate speech-language pathology programs with an emphasis in EI, ECSE, or EI/ECSE combined. Additional qualitative findings also indicated that a limited availability of shared coursework and the placement of the graduate program at the university in a medically-based or educationally-based department could influence the collaborative relationships and emphasis in the program.

Findings revealed that graduate programs are offering collaborative opportunities through optional shared coursework, mandatory coursework, and shared seminars where speech-language pathology students learned alongside students from other programs. While a majority of the programs that responded to the survey indicated that they have courses focused on foundations and assessment, there was a demonstrated need for shared coursework in the areas of family and curriculum.

Best practices in graduate training programs support the integration of courses that are focused on foundations in early intervention/early childhood special education, assessment, and familyguided early intervention because early intervention and early childhood are settings in which SLPs work with young children (Division of Early Childhood, 2014; National Association for the Education of Young Children, n.d.). Coursework in curricular approaches is a focus of EI/ECSE programs, but it is not a focus of speech-language pathology programs, as SLPs are not responsible for direct curriculum instruction. However, an understanding by SLPs of how to best support and collaborate within specific curricular models will enhance interprofessional collaborations when providing team-based instruction and intervention, thus providing the best outcomes for young children with disabilities. Shared coursework is consistent with current speech-language pathology IPE models in the literature (Barton et al., 2012; Miolo \& DeVore, 2016).

Although graduate speech-language pathology programs who responded to the survey expressed challenges to implementing shared coursework, qualitative findings revealed that programs have successfully engaged students in collaborative relationships in on-campus and off-campus clinical experiences. Within these clinical settings, findings indicated that students had the unique opportunity to engage with pre-professional and professionals other than SLPs to apply content learned. The results are similar to the literature that states clinical experiences are most effective when students have the opportunity to engage in collaborations that resemble real world practice 
(Barton et al., 2012; Hammick, Freeth, Koppel, Reeves, \& Barr, 2007). Additionally, experiencing team-based opportunities prior to graduation is an effective component of interprofessional graduate training programs (Barton et al., 2012). Thus, opportunities to engage in team-based decision making during clinical experiences can better prepare SLPs to be active, collaborative team members.

Although programs without federal funding reported difficulty in engaging in collaborative research, programs that did receive federal funding indicated that grant and research activities were mechanisms for collaborative practice among graduate speech-language pathology programs. For example, one program reported "We collaborate through Department of Education training grants." Another program reported "Our graduate SLP program has an emphasis in technology grant funded by the federal Department of Education. Students funded by this grant take courses in the graduate education program along with their SLP coursework." Programs who received grants were federal in nature and were geared toward personnel preparation such as the Leadership in Neurodevelopmental and Related Disabilities (LEND) grant and Office of Special Education (OSEP) Personnel Preparation grants. Further exploration of funding details is needed to determine how and why funding can support interprofessional collaborations.

In conclusion, the respondents who participated in this survey indicated that despite barriers, graduate speech-language pathology programs are implementing IPE and promoting collaborative relationships with EI/ECSE departments. Their collaborative relationships can be used as a model for other graduate speech-language pathology programs. Specifically, respondents provided unique ways to implement collaborative relationships through shared coursework, clinical experiences, and research activities. Next steps in this line of research will include an analysis of the responses collected through a separate mixed-methods survey to graduate EI/ECSE programs. These results will provide information regarding collaboration from the EI/ECSE perspective. Further analysis will compare the results from both surveys.

\section{Limitations}

While CAA accreditation requirements for IPE support collaboration, findings from this study offered an initial snapshot of current collaborative relationships between graduate speech-language pathology and EI/ECSE programs. Although great efforts were made to increase the sample size, the number of survey respondents limits the generalizability of this study's findings. Similarly, even though recommendations were followed to develop simplified survey questions, the simple questions limited the expanse of information collected. Though researchers operationally defined the term collaborative relationships, the term emphasis was not defined. Some respondents indicated difficulty interpreting the term emphasis and may have provided different responses if this term was also defined.

In an effort to provide additional data analyses, a follow-up survey could be conducted to collect additional information. Data such as the size of each graduate speech-language pathology program could be used to correlate the types of collaborative relationships to better understand patterns related to program size and other factors. Future research would benefit from a larger sample size to explore group differences. 


\section{Future Research}

Although this study begins to address the knowledge-to-practice gap in implementing IPE in graduate speech-language pathology programs, there is much more to be learned. Future research is needed to explore the perspectives regarding interprofessional collaborations among special education faculty and related service faculty. The results collected during this investigation will provide perspectives for comparison between the perspectives of speech-language pathologist, special education, and other related service faculty.

\section{References}

American Speech Language Hearing Association. (2018). Planning your education in communication sciences and disorders [Webpage]. Retreived from https://www.asha.org/Students/Planning-Your-Education-in-CSD/

American Speech Language Hearing Association. (2017). CEO Update May 2017 [Webpage]. Retrieved from http://www.asha.org/About/governance/CEO-Updates/CEO-UpdateMay-2017/

American Speech Language Hearing Association. (2013). Final report interprofessional education [Webpage]. Retrieved from https://www.asha.org/uploadedFiles/Report-AdHoc-Committee-on-Interprofessional-Education.pdf

American Speech Language Hearing Association. (2008). Roles and responsibilities of speech-language pathologists in early intervention: Guidelines [Webpage]. Retrieved from http://www.asha.org/policy/gl2008-00293.htm

Barton, E., Moore, H., \& Squires, J. (2012). Preparing speech language pathology students to work in early childhood. Topics in Early Childhood Special Education, 32(1), 4-13. doi: $10.1177 / 0271121411434567$

Brebner, C., Jovanovic, J., Lawless, A., \& Young, J. (2016). Early childhood educators' understanding of early communication: Application to their work with young children. Child Language Teacher and Therapy, 32(3), 277-292. doi: 10.1177/0265659016630034

Buring, S. M., Bhushan, A., Broeseker, A., Conway, S., Duncan-Hewitt, W., Hansen, L., \& Westberg, S. (2009). Interprofessional education: Definitions. student competencies, and guidelines for implementation. American Journal of Pharmaceutical Education, 73(4). Retrieved from http://www.ajpe.org/

Copple, C., Bredekamp, S., \& National Association for the Education of Young Children. (2009). Developmentally appropriate practice in early childhood programs serving children from birth through age 8 (3rd ed.). Washington, D.C: National Association for the Education of Young Children.

Council on Academic Accreditation. (2017). Standards for accreditation of graduate education programs in audiology and speech-language pathology [Webpage]. Retrieved from https://caa.asha.org/wp-content/uploads/Accreditation-Standards-for-Graduate-Programs

Crais, E. R., Boone, H. A., Harrison, M., Freund, P., Downing, K., \& West, T. (2004). Interdisciplinary personnel preparation: Graduates' use of targeted practices. Infants and Young Children, 17, 82-93. doi: 10.1097/00001163-200401000-00010

Division for Early Childhood. (2017). Position statement on personnel standards in early childhood special education [Webpage]. Retrieved from 
https://www.decdocs.org/position-statement-personnel-standa

Division for Early Childhood. (2014). DEC recommended practices in early intervention/early childhood special education 2014 [Webpage]. Retrieved from http://www.dec-sped.org/recommendedpractices

Evergreen, S., Gullickson, A., Mann, C., \& Welch, W. (2011). Developing \& validating survey instruments. [Webinar]. Retrieved from https://www.colorado.edu/ibs/decaproject/pubs/instrument-design-webinar-handout.pdf

Goldberg, L. R. (2015). The importance of interprofessional education for students in communication science and disorders. Communication Disorders Quarterly, 36(2), 121-125. doi:10.1177/1525740114544701

Hammick, M., Freeth, D., Koppel, I., Reeves, S., Barr, H. (2007). A best evidence systematic review of interprofessional education: BEME guide no. 9. Medical Teacher, 29, 735751. doi: 10.1080/01421590701682576

Howell, D. M., Wittman, P., \& Bundy, M. B. (2012). Interprofessional clinical education for occupational therapy and psychology students: A social skills training program for students with autism spectrum disorders. Journal of Interprofessional Care, 26(1), 49-55. doi: 10.3109/13561820.2011.620186.

Interprofessional Education Collaborative. (2018) Vision and Mission [Webpage]. Retrieved from https://www.ipecollaborative.org/vision---mission.html

Johnson, A. (2016). Interprofessional education and interprofessional practice in communication sciences and disorders: An introduction and case-based examples of implementation in education and health care settings. Retrieved from http://www.asha.org/uploadedFiles/IPE-IPP-Reader-eBook.pdf

Jones, M., \& Harris, A. (2014). Principals leading successful organizational change: Building social capital through disciplined professional collaboration. Journal of Organizational Change Management, 27(3), 473-485. doi: 10.1108/JOCM-07-2013-0116

Kinsella-Meier, M. A., \& Gala, N. M. (2016). Collaboration: Definitions and explorations of an essential partnership. Odyssey: New Directions in Deaf Education, 17, 4-9. Retrieved from http://www3.gallaudet.edu/clerc-center/our-resources/odyssey-magazine.html

McDonald, D., Proctor, P., Gill, W., Heaven, S., Marr, J., \& Young, J. (2015). Increasing early childhood educators' use of communication-facilitating and language-modeling strategies: Brief speech and language therapy training. Child Language Teaching and Therapy, 31(3), 305-322. doi: 10.1177/0265659015588203

MGH Institute of Health Professions. (2017) Impact Practice Three-Course Sequence. Retrieved from https://www.mghihp.edu/academics/impact-practice-three-coursesequence

Miles, M., Huberman, A., \& Saldana, J. (2014). Qualitative data analysis (3rd Edition). Los Angeles, California: SAGE Publications.

Miolo, G. \& DeVore, S. (2016). Speech language pathology and education students engage in interprofessional collaborative practice to support children with special needs in preschool settings. Journal of Interprofessional Education \& Practice, 4, 81. doi: /10.1016/j.xjep.2016.06.004

Morton, D. K., Bandera, E. M., Robinson, E. M., \& Atatoa Carr, P. E. (2012). In the 21st century, what is an acceptable response rate? Australian and New Zealand Journal of Public Health, 36(2), 106-108. doi: 10.1111/j.1753-6405.2012.00854.x

National Association for the Education of Young Children (n.d.). The 10 NAEYC Program 
Standards [Webpage]. Retrieved from

https://families.naeyc.org/accredited-article/10-naeyc-program-standards

National Center for Interprofessional Practice and Education. (2017). About interprofessional practice and education [Webpage]. Retrieved from https://nexusipe.org/informing/aboutipe

Nochajski, S. M. (2002). Collaboration between team members in inclusive educational settings. Occupational Therapy in Health Care, 15(3-4), 101-112. doi: 10.1080/J003v15n03_06

Pickering, J., \& Embry, E. (2013). So long, silos. The ASHA Leader, 18, 38-45. doi:10.1044/leader.FTR1.18062013.38.

Rogers, M. \& Nunez, L. (2013). From my perspective: How do we make interprofessional collaboration happen? The ASHA Leader, 18, 7-8. doi: 10.1044/leader.FMP.18062013.7

Self, T. L., Mitchell, L. M., Hess, S., Marble, K., J., \& Swails, J. (2017). Developing a university-based interprofessional education diagnostic team to identify children with possible autism spectrum disorder. Communication Disorders Quarterly, 38(3), 185-192. doi: $10.1177 / 1525740116655774$

Smith, J. (2010). An interdisciplinary approach to preparing early intervention professionals: A university and community collaborative initiative. Teacher Education and Special Education, 33(2), 131-142. doi: 10.1177/0888406409357546

Thomas, D. R. (2006). A general inductive approach for analyzing qualitative evaluation data. American Journal of Evaluation, 27(2), 237-246. doi: 10.1177/1098214005283748

University of South Carolina. (2018). Interprofessional Education [Webpage]. Retrieved from http://ipe.sc.edu/

University of Toronto (2016). Interprofessional Education [Webpage]. Retrieved from http://ipe.utoronto.ca/

U.S. Department of Education. (2016). 38th annual report to Congress on the implementation of the Individuals with Disabilities Education Act [PDF]. Retrieved from https://www2.ed.gov/about/reports/annual/osep/2016/parts-b-c/38th-arc-for-idea.pdf

Yang, C., Hossain, S. Z., \& Sitharthan, G. (2013). Collaborative practice in early childhood intervention from the perspectives of service providers. Infants \& Young Children, (26)1, 57-73. doi: 10.1097/IYC.0b013e3182736cbf 


\section{Appendix}

Survey Questions

University of Nevada, Reno Pre-Professional Collaboration Project for Speech-Language Pathologists

1. Do you have an accredited graduate program in speech-language pathology? (eligibility question)

2. Does your Speech-Language Pathology graduate program have an emphasis in Early Intervention (0 to 3 years)?

3. Does your Speech-Language Pathology graduate program have an emphasis in Early Childhood Special Education (3 to 8 years)?

4. Does your Speech-Language Pathology graduate program have an emphasis in both Early Intervention/Early Childhood Special Education combined?

5. Does your Speech-Language Pathology graduate program have a collaborative relationship with: Special Education Department? Early Childhood Special Education Department? Early Intervention Department?

6. Does your university have a graduate program in Early Intervention/Early Childhood Special Education?

7. Does coursework in your Speech-Language Pathology graduate program include entire classes focused on:

- Foundations in Early Intervention

(Description: Guiding principles of EI/ECSE; typical and atypical child development)?

- Assessment and Evaluation of Young Children (Description: Best practices in assessment for screening, eligibility, programming, and evaluation with young children)

- Family-Guided Early Intervention

(Description: Principles and practices for working with families in EI/ECSE; family systems theory, family assessment)?

- Curriculum Approaches in Early Childhood

(Description: Curricular approaches for working with young children in early childhood settings; designing and implementing early childhood curricula)?

8. Does coursework in your Speech Language Pathology graduate program use the following World Health Organization's "Interprofessional Core Competencies"?

- Teamwork

- Roles/Responsibilities

- Communication

- Learning and Reflection

- Patient (Child)

- Ethics/Attitudes

9. Describe any collaborative experiences with Early Intervention or Early Childhood Special Education university colleagues on your campus. If none, please indicate. (openended)

10. Please indicate your university affiliation. (open-ended) 